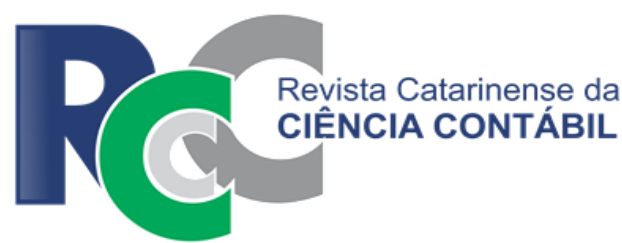

\title{
ANTECIPAÇÃO DE RECEBÍVEIS NOS BANCOS VRS FACTORINGS: UMA ANÁLISE DAS DIFERENÇAS ENTRE AS TAXAS COBRADAS E SUAS POSSÍVEIS CAUSAS
}

\section{ANTICIPATION OF RECEIVABLES IN BANKS VRS FACTORINGS: AN ANALYSIS OF THE DIFFERENCES BETWEEN THE RATES CHARGED AND THEIR POSSIBLE CAUSES}

\section{TATIELI BORGES MACHADO}

Graduada em Ciências Contábeis pela Universidade Federal de Santa Catarina (UFSC). Pós-Graduanda em Auditoria Contábil e Controladoria pelo Instituto de Consultoria Empresarial e Pós Graduação (ICEP). Endereço: Rua Manoel Rosa, 116 | Areias / São José/SC / Brasil.

E-mail: tatieli_machado@hotmail.com

\section{ALEX MUSSOI RIBEIRO}

Doutor em Controladoria e Contabilidade pela Universidade de São Paulo (USP). Professor Adjunto e Pesquisador da Universidade Federal de Santa Catarina (UFSC). Endereço: Campus Reitor João David Ferreira Lima CCN/CSE, 115 | Trindade / Florianópolis/SC / Brasil.

E-mail: alex.mussoi@ufsc.br

\section{RESUMO}

Este artigo tem como objetivo analisar a diferença entre as taxas médias utilizadas por bancos comerciais e empresas de fomento (factoring) na negociação de recebíveis das empresas no cenário brasileiro. As variáveis analisadas foram as taxas efetivas médias aplicadas pelas instituições financeiras e pelas companhias de fomento na compra de duplicatas e cheques, entre os anos de 2012 e 2016. Os testes estatísticos utilizados foram o de médias paramétrico para amostras independentes, a estatística D-Cohen e a análise de correlação. Os dados utilizados da pesquisa foram obtidos no site do Banco Central do Brasil (BACEN) e da Associação Nacional de Fomento Comercial (ANFAC). Os resultados evidenciam uma diferença de $1,35 \%$ a maior no fator ANFAC em relação às taxas médias cobradas pelos bancos. A estatística D-Cohen comprova que tal diferença é significativa e relevante. Com base na correlação foi possível inferir que uma possível causa para tal diferença reside nos métodos adotados entre os modelos de análise do risco de crédito utilizados em tais entidades e o ambiente menos burocrático e mais flexível em que as factorings atuam. As contribuições obtidas com esta pesquisa permitem direcionar os usuários que buscam a antecipação de recebíveis como modalidade de crédito e diminuem um pouco a carência de estudos relacionados com as agências de fomento no Brasil, principalmente dentro de uma perspectiva empírica.

Palavras-chave: Bancos. Factoring. Fator ANFAC. D-Cohen. 


\begin{abstract}
This article aims to analyze the difference between the average rates used by commercial banks and factoring companies in the negotiation of corporate receivables in the Brazilian scenario. The variables analyzed were the average effective rates applied by financial institutions and factoring companies in the purchase of trade acceptance bills and checks between the years of 2012 and 2016. The statistical tests used were the parametric means test for independent samples, the D-Cohen statistic and the correlation analysis. The data used in the research were obtained on the website of the Central Bank of Brazil (BACEN) and the National Factoring Association (ANFAC). The results show a difference of $1.35 \%$ greater in the ANFAC factor in relation to the average rates charged by the banks. The $D$-Cohen statistic has shown that such a difference is significant and relevant. Based on the correlation, it was possible to infer that a possible cause for such a difference lies in the methods adopted between the credit risk analysis models used in such entities and environment more flexible and the less bureaucratic in which factoring companies operates. The contributions obtained with this research allow us to direct the users that seek the anticipation of receivables as a credit modality and break the lack of studies related to the factoring agencies in Brazil, mainly from an empirical perspective.
\end{abstract}

Keywords: Banks. Factoring. ANFAC Factor. D-Cohen.

\title{
1 INTRODUÇÃO
}

Empresas com os recursos próprios, muitas vezes, não conseguem manter-se de forma competitiva no mercado ou até mesmo fazer a liquidação em dia de seus débitos perante funcionários, fornecedores e o governo. De acordo com os dados divulgados de uma pesquisa realizada pelo Serviço de Apoio às Micro e Pequenas Empresas (SEBRAE) de São Paulo (2010), mais da metade das companhias analisadas que iniciaram suas atividades antes de 2010 fecharam suas portas em um período de até cinco anos. Uma das principais dificuldades apontadas pelos entrevistados no estudo foi a carência de recursos financeiros para gerenciar suas obrigações de curto prazo. Outra pesquisa realizada pelo SEBRAE de São Paulo em 2014 destacou que, já no primeiro ano de atividades de uma empresa, a falta de capital (caixa) é tida como a segunda dificuldade mais significativa para continuar o negócio, perdendo apenas para a dificuldade de formação de clientes.

Como pode ser observado pelos resultados obtidos com as pesquisas do SEBRAE, a gestão adequada do caixa é crucial para sobrevivência e sustentabilidade econômica tanto das grandes quanto das pequenas organizações. A tarefa de gerir o caixa de uma empresa, por outro lado, não é simples e envolve uma série de questões complexas que podem ser gerenciadas ou não pelos responsáveis pelo negócio. (ex: prazo de pagamentos de fornecedores e recebimento de clientes; pagamentos de funcionários e seus benefícios; roubos, fraudes e etc.). Gitman e Zutter (2012) apontam que a gestão do capital circulante de uma companhia é uma das tarefas mais desafiadoras e que consomem mais tempo dos gestores financeiros.

Embora seja uma tarefa desafiadora, a gestão do caixa de uma empresa pode ser auxiliada por bancos ou empresas financeiras que, se necessário, podem fornecer recursos para a entidade saldar suas obrigações de curto prazo. Entre os recursos mais comuns para esse tipo de necessidade estão os empréstimos de capital de giro e a negociação de recebíveis.Em uma pesquisa realizada por Araújo e Machado (2007), com empresas da Paraíba os estudiosos encontraram que quase metade das pequenas empresas analisadas utiliza o desconto de cheques como forma de financiar seu caixa e mais da metade recorrem a bancos para empréstimos de capital de giro.

Os empréstimos de capital de giro apresentam como vantagem uma alta agilidade na obtenção do crédito e, na maioria dos casos, a não obrigatoriedade de fornecer uma garantia real na operação, tendo em vista que os bancos e as financeiras calculam um limite prévio, com base no score de crédito da entidade. A grande desvantagem dessas operações de capital 
de giro é o custo financeiro do empréstimo, que está entre as taxas mais altas cobradas no mercado.

Uma segunda operação, também comum para ajudar a gestão de curto prazo do caixa, é a antecipação de recebíveis. Segundo a norma internacional de contabilidade para ativos financeiros, International Financial Reporting Standard (IFRS) nove, existem duas modalidades principais de antecipação de recebíveis: (1) uma que transfere substancialmente o risco do instrumento financeiro para quem adquire o título e (2) uma em que a companhia detentora fica com os riscos de não pagamento do título, utilizando o instrumento financeiro como uma mera garantia para sua captação de recursos junto ao banco(IASB, 2014).

A primeira forma de antecipação de recebíveis é conhecida pelo mercado como venda de recebíveis (securitização). Nela ocorre a efetiva venda do título e a sua respectiva baixa contábil pelo vendedor. A segunda forma de antecipação, por sua vez, é conhecida como desconto de cheques ou duplicatas (ou das vendas parceladas pelo cartão de crédito) e é a modalidade mais comum, principalmente no âmbito das companhias de pequeno porte. Nessa situação ocorre apenas a transferência de fundos do banco (ou operadora financeira) para a empresa que cede em garantia as duplicatas ou os cheques que tem a receber. $O$ tratamento contábil do segundo tipo de operação é o mesmo da contabilização de um empréstimo. As taxas que o banco ou financeira cobram fazem parte do custo efetivo da operação e devem possuir tratamento contábil como tal, ou seja, devem ser incluídos no custo efetivo do financiamento. A grande vantagem dessa modalidade em relação ao empréstimo de giro são as taxas cobradas, substancialmente menores do que as de empréstimos sem garantia.

Para captar recursos com a antecipação de duplicatas ou cheques uma organização pode recorrer a um banco comercial ou a uma empresa de fomento (factorings). O banco faz a intermediação de recursos financeiros, capta e empresta dinheiro da poupança popular. $O$ capital é absorvido juntamente a agentes superavitários e entregue para agentes deficitários. Já a factoring opera com recursos próprios, presta serviços de cobrança e compra os créditos (direitos) direto de seus clientes. No desconto bancário, o custo da operação de antecipação para o cliente é medido pela taxa efetiva que representa o seu risco de crédito, o spread do banco (diferença entre o custo da captação e o da aplicação do valor obtido no mercado), os tributos e a tarifa que o banco cobra pela operação. Nas factorings o custo da antecipação é medido pelo fator de compra. Esse fator representa a taxa efetiva cobrada pelas empresas de fomento juntamente com a sua margem e seus custos diretos e indiretos totais (Anfac, 2017; Capelletto \& Corrar, 2008; Gonçalves, Gouvêa, \& Mantovani, 2013; Leite, 2011; Wolf, 2008).

Apesar de formalmente os bancos e as factorings possuírem concepções de atividades e maneiras de financiamento distintas, nas operações de antecipação de recebíveis, essencialmente, eles fazem a mesma coisa, emprestam recursos com base na garantia do título a ser recebido. As taxas cobradas pelo banco e o fator das factorings, não obstante refletirem situação e os custos particulares das operações de crédito, também representam a mesma para quem precisa de recursos, o custo efetivo da operação. Mesmo assim, diversos autores, como Cochrane (2005), Dodl (2006), Falcão (2001), Goulart e Paulo (2011), Leite (2011) e Wolf (2008), destacam a relevância do papel das factorings para o financiamento da economia, principalmente, as mais informais, tendo em vista que o processo de obtenção de crédito em tais entidades não é tão exigente como nos bancos (essa menor exigência pode ser comprovada na pesquisa de Anjos, Miranda, Silva e Freitas, (2012), de acordo com a qual apenas 3\% dos entrevistados apontam as factorings demandantes de informações contábeis mais complexas enquanto os bancos representam $53 \%$ dos casos).

É natural que em um ambiente menos criterioso existam maiores riscos nas operações e isso deve se refletir nas taxas cobradas e nos custos de captação para o mercado. Mas até que ponto esse custo gera uma diferença significativa nas taxas praticadas pelas factorings quando comparadas com as dos bancos comerciais? Stabile (2012), em seu ensaio teórico, aponta que os custos das operações de crédito com as factorings são maiores do que os das operações com os bancos, mas não investiga o tamanho nem a relevância dessa diferença.

Dentro desse contexto, este trabalho pretende analisar a diferença entre as taxas médias utilizadas por bancos comerciais e empresas de fomento (factoring) na negociação de recebíveis das empresas no cenário brasileiro. Mais pontualmente, esta pesquisa analisou as diferenças nas taxas efetivas cobradas pelas agências de fomento e pelos bancos comerciais 
em um horizonte de 5 anos (2012 - 2016). Adicionalmente, foram realizadas análises auxiliares para medir o tamanho do efeito econômico das diferenças entre as taxas cobradas e os possíveis drivers macroeconômicos dessas relações.

Trabalhos como os feitos por Batista e Junior (2012) e Silveira (2010) criaram uma espécie de relevância "mística" ao redor do papel das factorings no desenvolvimento econômico regional, principalmente no âmbito das pequenas empresas. O intuito desta pesquisa é contribuir com dados empíricos e mostrar que, embora as factorings tenham um papel relevante na distribuição de recursos no mercado de antecipação de recebíveis, as taxas cobradas refletem risco maior de suas operações e são significativamente maiores do que as taxas cobradas pelos bancos comerciais. Em termos práticos, esta pesquisa pode servir de base, também, para agentes econômicos decidirem o veículo utilizado para anteciparem seus recebíveis, dadas as suas condições de crédito.

\section{FUNDAMENTAÇÃO TEÓRICA}

\subsection{Empresas de Factoring e bancos comerciais como agentes financiadores do capital de giro}

Não obstante Gitman e Zutter (2012) apontarem o alto grau de dificuldade que existe em calibrar uma política financeira adequada para uma gestão de sucesso do capital de giro, existem algumas ferramentas que podem ajudar o gestor financeiro nessa empreitada. Entre essas ferramentas está o desconto de duplicatas ou de cheques. Uma empresa que decide antecipar seus recebíveis pode recorrer aos bancos comerciais ou às agências de fomento (factorings).

Para Leite (2011), o factoring caracteriza-se como uma atividade comercial mista atípica, que envolve prestação contínua de serviços, juntamente com a compra de direitos creditórios resultantes de vendas mercantis ou de prestação de serviços realizadas a prazo. A Lei no 9.430/96, em seu art. 58, inciso XV, indica as factorings como empresas:

$X V$ - que explorem as atividades de prestação cumulativa e contínua de serviços de assessoria creditícia, mercadológica, gestão de crédito, seleção e riscos, administração de contas a pagar e a receber, compras de direitos creditórios resultantes de vendas mercantis a prazo ou de prestação de serviços (factoring).

Markusons (1997, como citado em Wloch, 2006, p.13) descreve a utilização dos serviços prestados pelas fomentadoras como um importante instrumento para empresas que possuem restrições e não conseguem operar com Bancos, na medida em que o nível de exigência e burocracia são diferentes. A flexibilidade para abertura de cadastro e para a concessão do crédito é maior do que em outras instituições, pois o contato da fomentadora é mais próximo com a empresa cliente. Outra vantagem é que o foco das factorings é a compra dos recebíveis. Por isso, não exigem dos clientes reciprocidade; como a venda de seguros, capitalizações e consórcios (Diário do comércio, 2016; Gonçalves, 2012).

Dessa forma, as factorings auxiliam como suporte para suas empresas clientes e contribui em para o crescimento, a continuidade e o desenvolvimento dessas empresas no mercado. Portanto, as factorings podem atuar para fomentar e auxiliar as pequenas e médias empresas com os problemas de fluxo de caixa do dia a dia. Isso possibilitaria um crescimento mais rápido do negócio e uma maior rotatividade do seu capital de giro. A atividade também dispõe de uma rapidez que outros sistemas não oferecem (Katayama, 2003; Santos, 2014; Silveira, 2010; Sinfac-SP, 2016; Wolf, 2008).

A atividade de um banco comercial, por outro lado, é de intermediação financeira. Os bancos captam recursos da poupança popular e investem em atividades que demandam recursos. Taylor (2013) aponta que o capital dos bancos é formado por depósitos de seus correntistas e que o seu resultado deriva da diferença entre a taxa paga para captar esses depósitos da taxa cobrada dos que necessitam desse capital. Na visão de Taylor (2013), os 
melhores bancos serão aqueles que captam mais barato e emprestam mais caro dentro de um determinado nível de risco de crédito.

Em uma operação de desconto de duplicatas ou cheques, contudo, o papel das factorings e dos bancos comerciais possuem uma grande similaridade. Em ambos os casos, 0 agente financeiro cede recursos aos clientes. Toma como garantia os recebíveis vinculados. A principal diferença entre as duas operações, nesse caso, seria a forma como elas são financiadas. Nos bancos o capital é regulado e financiado pelos depositários. Nas agências de fomento, por sua vez, o capital empregado é, muitas vezes, próprio e isso dá maior flexibilidade ao investimento. Como consequência, as factorings podem ceder recursos a clientes que os bancos não cederiam em função, por exemplo, de o mesmo possuir restrições cadastrais. Esse aspecto foi apontado na pesquisa de Eckert, Rizzon, Mecca e Biasio(2015).

Além disso, os bancos comerciais precisam da autorização do Banco Central para funcionar, diferentemente das fomentadoras que não necessitam de tal autorização (Gonçalves, 2012). Falcão (2001, p.4) cita factoring como "uma sociedade mercantil, limitada ou anônima, cuja existência legal nasce com o arquivamento de seus atos constitutivos na Junta Comercial".

\subsection{Crédito e risco}

A palavra crédito tem como origem o latim creditum e significa confiança ou segurança de alguma coisa (Securato, 2002). De acordo com Schrickel (1997, p.25), "crédito é todo ato de vontade de alguém em destacar ou ceder, temporariamente, parte de seu patrimônio a um terceiro, com a expectativa de que esta parcela volte a sua posse integralmente, após decorrer o tempo estipulado".

O crédito pode ser deliberado como um importante instrumento no desenvolvimento de uma economia, pois visa a financiar e fomentar os agentes deficitários, tais como o Estado, empresas e famílias (Palmuti \& Picchiai, 2012).

No contexto deste trabalho, crédito consiste no ato de dispor a uma empresa um determinado valor como pagamento pela negociação de um título com vencimento futuro, e com a expectativa de pagamento do título por outra empresa, que comprou um determinado produto ou teve a prestação de um serviço, após o período acordado. Desse modo, representa a expectativa da instituição, que colocou o valor no mercado, de recebê-lo em uma data futura (Brito \& Assaf, 2008a; Brito \& Assaf, 2008b; Silva, 2014).

No entanto, o fato de existir uma expectativa de retorno futuro acarreta na existência de um risco de ela não ser realizada. O crédito envolvido na operação está associado ao risco do tomador não efetuar a liquidação nas condições pactuadas. Esse risco é conhecido como risco de crédito e, conforme definição de Jorion (2011),é o risco de uma perda econômica derivada da falha de uma contraparte cumprir suas obrigações contratuais, ou seja, deixar de pagar o combinado.

No caso dos bancos e das factorings esse é o principal risco subjacente às suas operações de antecipação de recebíveis. Jorion (2011) compõe o risco de crédito com base em três elementos: risco de não pagamento (default), risco de recuperação e risco de mercado. Para o autor, o risco de default e o risco de recuperação podem ser gerenciados mas o risco de mercado afeta todo o sistema. Embora o risco de crédito, inerente à atividade de antecipação dos bancos e das factorings, não seja passível de eliminação em sua totalidade, ele pode ser minimizado por meio de uma eficiente gestão. (Brito, Assaf \& Corrar, 2009; Capelletto \& Corrar, 2008; Dantas, Rodrigues, Rodrigues, \& Capelletto, 2010; Palmuti \& Picchiai, 2012; Schrickel, 1997; Silva, 2014; Souza, 2015).

Jorion (2011) aponta três drivers principais para determinação do risco de crédito: (1) a probabilidade de não pagamento (default), (2) a exposição de crédito e (3) a perda real decorrente do default (é a perda menos o que foi recuperado). Quando se trata de negociação de recebíveis surge ainda mais um elemento, que é a probabilidade de default do tomador original da obrigação. No caso dos bancos esse risco é gerenciado diretamente com seu cliente. O banco avalia o crédito de quem vai fazer a operação de antecipação dos recebíveis. No caso do não pagamento da contraparte originária do título, o banco cobra o valor do com cliente que fez a antecipação. 
Portanto, o banco não entra no mérito da qualidade do recebível que ele pega em garantia, uma vez que possui o direito de regresso na operação. No caso das factorings esse direito de regresso ainda não está legalmente bem estabelecido, o que pode aumentar o foco da sua análise de risco, saindo apenas do cliente (como nos bancos) e incluindo, também, o devedor originário do título. Em suma, cada instituição, seja financeira ou não, pode analisar o risco envolvido nas operações de desconto a seu modo (Katayama, 2003; Silva, 2014). As instituições credoras precisam de políticas sólidas para mensurar e controlar tais riscos, com o intuito de não incorrer em insolvência e obter sucesso financeiro por meio do lucro (Capelletto \& Corrar, 2008).

Além do risco intrínseco do cliente e do título que estão envolvidos na negociação, existe o risco macroeconômico ou de mercado. Hull (2015) aponta que o risco de mercado está vinculado ao movimento futuro de variáveis de mercado. No caso da negociação de recebíveis, as variáveis de mercado que podem afetar o risco de crédito são: a taxa básica de juros representada pela Selic e o nível de inadimplência geral da economia. A sensibilidade ao risco de mercado é o único que consegue ser testado, pois não depende do modelo de crédito individual de cada banco ou financeira. A correlação da taxa do desconto de recebíveis praticadas pelas factorings e pelos bancos com as variáveis de mercado pode ser um sinalizador da complexidade dos modelos de análise de crédito presentes em tais entidades. Quanto mais correlacionados com o risco de mercado menor será o peso que o risco da análise individual do cliente vai possuir na composição do risco de crédito total.

No caso dos bancos é esperada uma correlação menor, pois seus modelos conseguem avaliar as particularidades de cada cliente ou portfólio de clientes com maior exatidão, o que torna seu modelo menos susceptível às flutuações gerais da economia. No caso das factorings é o contrário. É esperada uma correlação maior com as variáveis econômicas pelo fato de não investirem em modelos tão sofisticados como os bancos.

No modelo de risco bancário são utilizados programas estatísticos para classificar as empresas clientes conforme sua probabilidade de default. Dependendo do resultado do teste a empresa se encaixa em um grupo de risco. A concessão do crédito também está atrelada aos modelos estatísticos utilizados e ao grupo em que a empresa se encaixa. O modelo é mais geral e possui maior exatidão (Gonçalves et. al., 2013; Palmuti \& Picchiai, 2012).

Além disso, os bancos, muitas vezes, operam com empresas maiores, que possuem uma análise de crédito feita por agências de rating, o que pode auxiliar na precisão de modelos de risco. Já nas factorings a análise é feita de modo individual a cada empresa cliente e a cada empresa devedora do título comprado, pois se entende que cada uma dessas empresas possui suas peculiaridades, seu modo de administrar e suas perspectivas de negócio. A classificação do risco é realizada de maneira mais flexível pelo gerente da empresa de factoring. A decisão de concessão do crédito é mais dinâmica e direcionada a cada situação (Diário do comércio, 2016; Lima, Ensslin, \&Montibeller, 2008; Wolf, 2008).Eckert et al. (2015) apontam, inclusive, que as agências de fomento são muito procuradas por empresas com restrições cadastrais devido à sua maior flexibilidade na concessão de crédito.

A visão dos riscos envolvidos nas operações pode afetar diretamente a taxa aplicada, uma vez que ela precisa absorver o risco de perda. Na taxa utilizada pelos bancos estão inclusos o custo do capital adquirido de terceiros, o spread bancário, o risco envolvido e os tributos. Na factoring a composição do fator de compra inclui o custo oportunidade do capital próprio, os custos fixos e variáveis, os impostos operacionais, as despesas de cobrança e a expectativa de risco e de lucro (Anfac, 2017; Gonçalves et. al., 2013).

\subsection{Pesquisas relacionadas}

Em âmbito nacional, os trabalhos encontrados referentes às factorings são mais teóricos e dificilmente apresentam dados empíricos. Em sua grande maioria, eles citam o que é a atividade e como ela pode auxiliar as empresas que precisam de capital de giro (Gonçalves, 2012; Silveira, 2010; Stabile, 2012). As que apresentam algum dado empírico utilizam questionário ou estudo de caso para embasar as suas análises e procuram investigar aspectos relacionados aos modelos de gestão das empresas de factoring ou os motivos que remetem as 
demais empresas a utilizarem seus serviços (Wolf, 2008; Decker\& Gomes, 2014; Rotta\& Lima, 2006; Eckert et al., 2015).

Entre os trabalhos teóricos de destaque, Gonçalves (2012) e Silveira (2010) descrevem a origem da atividade e o histórico no Brasil. Wolf (2008), por sua vez, apresenta a atividade e os procedimentos de análise para concessão de crédito utilizados por uma factoring.

Silveira (2010) e Wolf (2008) citam, ainda, a falta de interação entre a contabilidade e as agências de fomento. Segundo Silveira (2010), o contador precisa conhecer melhor essa modalidade, levando em consideração o número de empresas que utilizam os serviços. Isso evitaria problemas nos momentos de contabilização e agregaria conhecimento. A autora também evidencia que um pequeno número de factorings são administradas por profissionais da área contábil. Wolf (2008), em sua pesquisa, buscou apresentar por meio de entrevista e coleta de dados, as práticas adotadas por uma factoring para a concessão de crédito às suas empresas clientes. $\mathrm{O}$ autor sugeriu que a empresa estudada utilizasse mais os índices e os dados contábeis de seus clientes para as análises realizadas.

No que tange aos trabalhos relacionados ao risco de crédito, pode-se destacar os que foram desenvolvidos por Brito e Assaf Neto (2008a), Brito e Assaf Neto (2008b) e Brito, Assaf Neto e Corrar (2009). Os autores buscaram evidenciar modelos de classificação de riscos, com empresas listadas na BM\&FBOVESPA. Os dados utilizados foram índices econômicos financeiros, retirados da Comissão de Valores Mobiliários (CVM) ou do software Economática ${ }^{\circledR}$, a fim de classificar as empresas utilizadas nas amostras em solventes e insolventes, e após analisar os sistemas de classificação de riscos, avaliar os riscos dos créditos concedidos a empresas ou propor procedimentos para mensurar tais riscos. A técnica estatística utilizada nos três estudos foi a regressão logística, em que a variável dependente é categórica e assume um entre dois possíveis resultados (binária), como: "fracasso ou sucesso", "solvente ou insolvente".

A pesquisa realizada por Brito e Assaf Neto (2008a) teve como objetivo desenvolver um modelo de classificação de risco para mensurar o risco do crédito de empresas no cenário brasileiro. Os resultados indicam que o modelo de classificação de tais riscos, desenvolvido pelos autores, prevê eventos de default com um ano de antecedência e com bom nível de precisão. $O$ trabalho também indica que as demonstrações contábeis possuem informações que possibilitam a classificação das empresas como prováveis solventes ou prováveis insolventes.

O outro estudo desenvolvido pelos mesmos autores, Brito e Assaf Neto (2008b), propôs um conjunto de métodos para avaliar o risco de créditos concedidos por bancos a empresas. Foi utilizada uma abordagem conceitual simples. O modelo proposto utilizou uma metodologia baseada na simulação das variáveis explicativas de um modelo de creditscoring - método utilizado por instituições financeiras para verificar o risco de inadimplência da empresa solicitante do crédito. Os resultados obtidos com a pesquisa evidenciam que o modelo proposto pelos autores representa uma opção que permite ser o risco de carteiras de crédito mensurado.

Por fim, a pesquisa de Brito, Assaf Neto e Corrar (2009) examinou se eventos de default de companhias abertas no país poderiam ser previstos por um sistema de classificação de risco de crédito baseado em índices contábeis. O sistema proposto utilizou a análise de conglomerados para classificar as empresas em classes de risco. A variável utilizada para conferir a classificação de risco às empresas foi a probabilidade de default, prevista no modelo de risco de crédito elaborado por Brito e Assaf Neto (2008a). O sistema atribuiu ratings anuais para as empresas. Em seguida, foram geradas matrizes de migração de risco. Os resultados demonstram que o sistema de classificação de risco desenvolvido evidencia o risco das empresas insolventes previamente ao ano de ocorrência do default. A maioria dessas empresas foram classificadas nas piores classes de risco ou demonstraram migrações para classes inferiores nos anos posteriores ao default.

Em termos teóricos, este trabalho pode contribuir com evidências empíricas sobre a diferença no comportamento das taxas cobradas pelos bancos e pelas factorings nas operações de desconto de recebíveis. Como foi mencionado anteriormente, alguns trabalhos, como os de Stabile (2012) e Eckert et al. (2015), apontam vantagens e desvantagens de se operar com agências de factoring,mas sem uma contribuição empírica relevante. Esta pesquisa busca mostrar com dados que o custo de captação das operações de desconto de recebíveis 
nas agências de fomento é muito maior do que nos bancos e que esse custo pode estar atrelado ao modelo de análise do risco de crédito mais rudimentar e flexível utilizado.

\section{DESENHO DA PESQUISA}

\subsection{Coleta e organização de dados}

Para satisfazer o objetivo proposto neste trabalho, optou-se por uma abordagem quantitativa, de caráter descritivo, com a utilização das taxas médias cobradas por bancos e factorings na negociação de recebíveis entre os anos 2012 e 2016. Os dados das agências de fomento foram retirados do site da Associação Nacional de Fomento Mercantil (ANFAC), enquanto as variáveis bancárias foram obtidas no site do Banco Central do Brasil (BACEN).

A série histórica do fator de compra das factorings foi encontrada na revista Fomento Comercial, edição número 102 - referente aos meses de Outubro, Novembro e Dezembro de 2016 - presente no site da Anfac. Não foi necessário qualquer ajuste no fator, pois ele representa os custos gerais e a margem de lucro da captação de tais empresas.

As variáveis bancárias, encontradas no site do Bacen, foram obtidas em "taxa de juros". Foi selecionado "taxa de juros de operação de crédito", em seguida selecionado "histórico posterior a 01/01/2012". O campo seguinte foi alterado para pessoa jurídica e a modalidade para desconto de duplicata e posteriormente desconto de cheque. Isso foi feito, uma vez que o fator médio das factorings já havia sido obtido com a junção da compra de duplicatas e cheques e também de maneira mensal, ao mesmo tempo em que na taxa bancária precisou-se fazer a soma da taxa aplicada a duplicatas e cheques e calcular a taxa mensal, uma vez que a mesma foi encontrada em períodos semanais.

As taxas no site do Banco Central eram dispostas em intervalos de dias. Um período de dias se diferenciava do outro pela exclusão do último dia útil e a soma do dia útil subsequente. Como alguns dias se repetiam nos períodos, foram separados os intervalos de tempo, de modo que pudessem ser distintos, mas sem omitir qualquer dia. Na sequência foi calculada a soma das taxas dos bancos correspondente a cada período selecionado e dividida pelo número de bancos no intervalo de tempo do período, uma vez que a quantidade de bancos disposta no site mudava nos intervalos de dias. Algumas instituições não operaram nas modalidades nos períodos referidos ou não prestaram informações ao Banco Central.

Posteriormente, foram agrupados de forma aproximada para representarem as semanas de cada mês. Após, foram somadas as taxas dos grupos em períodos, que representavam as semanas, e divididos pela quantidade de semanas de cada mês. $O$ procedimento foi aplicado primeiramente para o desconto de duplicata e posteriormente para o desconto de cheque. Por fim, somando as taxas de duplicatas e cheques, visto que os períodos eram idênticos, e dividindo-as por dois, obteve-se a taxa mensal média dos bancos.

Essa taxa média representa a média das taxas cobradas por todos os bancos nos períodos de interstícios analisados. Como dentro dessa média existem bancos com características muito distintas e isto poderia influenciá-la, foi feita uma análise de sensibilidade apenas com as taxas cobradas pelos seis maiores bancos do país (para realizar a análise de sensibilidade): Sendo estes: Banco Bradesco, Banco do Brasil, Banco Santander, Caixa Econômica Federal, HSBC Bank Brasil (esse com dados dispostos até outubro de 2016, depois foi incorporado ao Banco Bradesco) e Itaú Unibanco. O processo de organização dos dados foi o mesmo aplicado à taxa de todos os bancos.

Para cumprir a meta de pesquisa foram obtidos também dados secundários, com o intuito de analisar o reflexo das diferentes taxas aplicadas na negociação dos recebíveis e nos modelos de risco aplicados. Os dados secundários foram a taxa SELIC e o indicador de inadimplência, ambos obtidos no site do Banco Central. Nenhum ajuste foi necessário a estas taxas.

A taxa SELIC foi apanhada em "taxa de juros", "taxa Selic diária"; foi selecionada a opção "fatores acumulados" e depois a opção mensal. O indicador de inadimplência foi encontrado na aba "economia e finanças", na guia "séries temporais", foi selecionada a opção "Acesso ao SGS (Sistema Gerenciador de Séries Temporais)", em seguida acessado "Atrasos 
e inadimplência", depois "Inadimplência", e posteriormente "Inadimplência de carteira pessoas Jurídicas - Total". Foi consultada a série, depois selecionado o período desejado e por fim consultados os valores.

Cabe destacar que as taxas utilizadas tanto das factorings quanto dos bancos são as taxas efetivas médias gerais, ou seja, não é considerado o risco de crédito de cada cliente. Essa é uma limitação do trabalho, pois as taxas cobradas entre os melhores e os piores clientes pode não variar de modo homogêneo.

\subsection{Testes estatísticos}

Para a análise dos dados foram utilizados três testes estatísticos principais: o teste de médias paramétrico de amostras independentes para verificar se as diferenças entre as taxas cobradas são estatisticamente significativas, a estatística D-Cohen para calcular o tamanho do efeito das diferenças entre as taxas e a correlação de Pearson para verificar a relação das taxas com outras medidas econômicas, no intuito de levantar possíveis justificativas para os resultados encontrados.

O primeiro teste realizado no trabalho foi o de médias de amostras independentes. O primeiro passo desse teste foi verificar a normalidade dos dados para se definir o tipo de teste aplicado: paramétrico ou não paramétrico. Os resultados (não apresentados) dos testes de normalidade comprovaram que os dados apresentam distribuição normal, portanto, optou-se pela utilização do teste de médias paramétrico (que seguem os parâmetros da distribuição normal). O segundo passo do teste de médias foi analisar a homogeneidade da variância entre as amostras de taxas. Nesse caso, a hipótese de homogeneidade foi rejeitada e foi necessário utilizar uma correção no teste que o deixa mais conservador, pois aumenta o erro padrão e o tamanho do intervalo de não rejeição da hipótese nula (de não significância estatística).

Para verificar o tamanho do efeito nas variáveis foi aplicada a estatística $D$ de Cohen (1998). De acordo com o autor, essa estatística retrata o grau em que o fenômeno está presente na população ou o grau em que a hipótese nula é falsa. Cohen (1998) ressalta que quanto maior for o tamanho de efeito, maior é o grau em que o fenômeno estudado se manifesta, e se a hipótese nula não for rejeitada ou a estatística $D$ contiver o zero dentro do seu intervalo de confiança é igual a dizer que o efeito é nulo. A fórmula do cálculo da estatística D utiliza a média das populações e o desvio padrão conjunto entre elas. Essa relação pode ser expressa pelo seguinte modo para um efeito não direcional (bicaudal):

$$
\mathcal{D}=\frac{\left|m_{A}-m_{B}\right|}{\sigma}
$$

Em que:

$m_{A}=$ Média da população A.

$m_{B}=$ Média da população B.

$\sigma=$ Desvio padrão conjunto das populações.

Por fim, foi feita uma análise de correlação das taxas dos bancos e do fator ANFAC com indicadores econômicos da taxa básica econômica e de inadimplência. Essa análise foi feita com o intuito de justificar as diferenças encontradas entre as taxas com base na relação delas com os indicadores econômicos.

A aplicação dos testes foi realizada com auxílio do software STATA13®. A descrição das variáveis utilizadas no trabalho está disposta na Figura 1. 


\begin{tabular}{|c|c|c|}
\hline Variável & Descrição & Fonte \\
\hline Fator Anfac & $\begin{array}{l}\text { Indicador que sinaliza o preço de referência de compra de créditos para o mercado do } \\
\text { fomento comercial (mero parâmetro). A composição do fator leva em conta os itens: } \\
\text { custo - oportunidade do capital próprio, custos fixos, custos variáveis, impostos } \\
\text { operacionais, despesas de cobrança e expectativa de risco / lucro. Na composição do } \\
\text { cálculo do fator, a ANFAC utiliza como indicativo do custo - oportunidade a taxa do } \\
\text { Certificado de Depósito Bancário - CDB (título emitido por instituição financeira de } 1^{\text {â }} \\
\text { linha, com taxa de juro prefixada por períodos de } 30 \text { dias). }\end{array}$ & ANFAC \\
\hline $\begin{array}{c}\text { Taxa } \\
\text { Bancária }\end{array}$ & $\begin{array}{c}\text { Correspondem a médias aritméticas ponderadas pelos valores das operações } \\
\text { contratadas nos cinco dias úteis referidos em cada período apresentado. Essas taxas } \\
\text { representam o custo efetivo médio das operações de crédito para os clientes, } \\
\text { composto pelas taxas de juros efetivamente praticadas pelas instituições financeiras } \\
\text { em suas operações de crédito, acrescidas dos encargos fiscais e operacionais } \\
\text { incidentes sobre as operações. }\end{array}$ & BACEN \\
\hline Taxa Selic & $\begin{array}{c}\text { Taxa média ajustada dos financiamentos diários apurados no Sistema Especial de } \\
\text { Liquidação e de Custódia (Selic) para títulos federais. Para fins de cálculo da taxa, são } \\
\text { considerados os financiamentos diários relativos às operações registradas e } \\
\text { liquidadas no próprio Selic e em sistemas operados por câmaras ou prestadores de } \\
\text { serviços de compensação e de liquidação (art. } 1^{\circ} \text { da Circular } n^{\circ} 2.900 \text {, de } 24 \text { de junho } \\
\text { de } 1999, \text { com a alteração introduzida pelo art. } 1^{\circ} \text { da Circular } n^{\circ} 3.119 \text {, de } 18 \text { de abril } \\
\text { de } 2002) .\end{array}$ & BACEN \\
\hline $\begin{array}{l}\text { Indicador de } \\
\text { Inadimplência }\end{array}$ & $\begin{array}{c}\text { Percentual da carteira de crédito do Sistema Financeiro Nacional com pelo menos } \\
\text { uma parcela com atraso superior a } 90 \text { dias. Inclui operações contratadas no segmento } \\
\text { de crédito livre e no segmento de crédito direcionado. }\end{array}$ & BACEN \\
\hline
\end{tabular}

Figura 1. Descrição das variáveis utilizadas na pesquisa

\section{APRESENTAÇÃO E ANÁLISE DOS RESULTADOS}

\subsection{Estatística descritiva}

Foram utilizados os dados mensais de cinco anos, de janeiro de 2012 a dezembro de 2016, totalizando sessenta observações para cada variável analisada. A média das taxas indica um valor superior do fator ANFAC em comparação com a taxa bancária, o que já era esperado em decorrência de um maior risco nas atividades de factoring. Os valores máximos e mínimos das duas principais variáveis também se diferem, mas dentro de um intervalo próximo de 1 ponto percentual. Já o desvio padrão do fator ANFAC foi bem maior do que o da taxa dos bancos. Esse maior desvio denota uma maior dispersão da taxa das factorings dentro do período analisado. Pode ser um indício da maleabilidade existente no processo de concessão de crédito das agências de fomento, pois a taxa sobe e desce dentro de um intervalo maior, ou seja, é uma taxa mais flexível do que a taxa dos bancos que se alteram dentro de um intervalo menor ao longo do tempo.

Tabela 1

Estatística das variáveis utilizadas na pesquisa

\begin{tabular}{lccccc}
\hline \multicolumn{1}{c}{ Variáveis } & $\begin{array}{c}\text { No de } \\
\text { Observações }\end{array}$ & Média & Desvio Padrão & Mínimo & Máximo \\
\hline ANFAC & 60 & 4,04 & 0,40 & 3,56 & 4,69 \\
BACEN & 60 & 2,68 & 0,28 & 2,34 & 3,45 \\
SELIC & 60 & 0,87 & 0,20 & 0,49 & 1,22 \\
INADIMPLÊNCIA & 60 & 2,35 & 0,46 & 1,80 & 3,61
\end{tabular}


A próxima análise feita foi verificar a tendência do comportamento das duas taxas dentro do período analisado. Isso está exposto na Figura 2. Percebe-se, com base no gráfico, que o fator ANFAC é constantemente maior do que a taxa dos bancos. A variação das taxas, por outro lado, mostrou que para os bancos houve um movimento mais radical de aumento na taxa no começo de 2016. Esse aspecto pode estar relacionado com algum movimento de deterioração econômica ocorrido no período, como, por exemplo, um aumento na taxa de inadimplência que não teve um reflexo tão radical nas factorings porque elas já operam em um ambiente de inadimplência maior. O trabalho realizado por Dodl (2006) também apresenta um gráfico com algumas modalidades de crédito, incluindo as variáveis fator ANFAC e taxa BACEN, em comparação com a taxa SELIC.

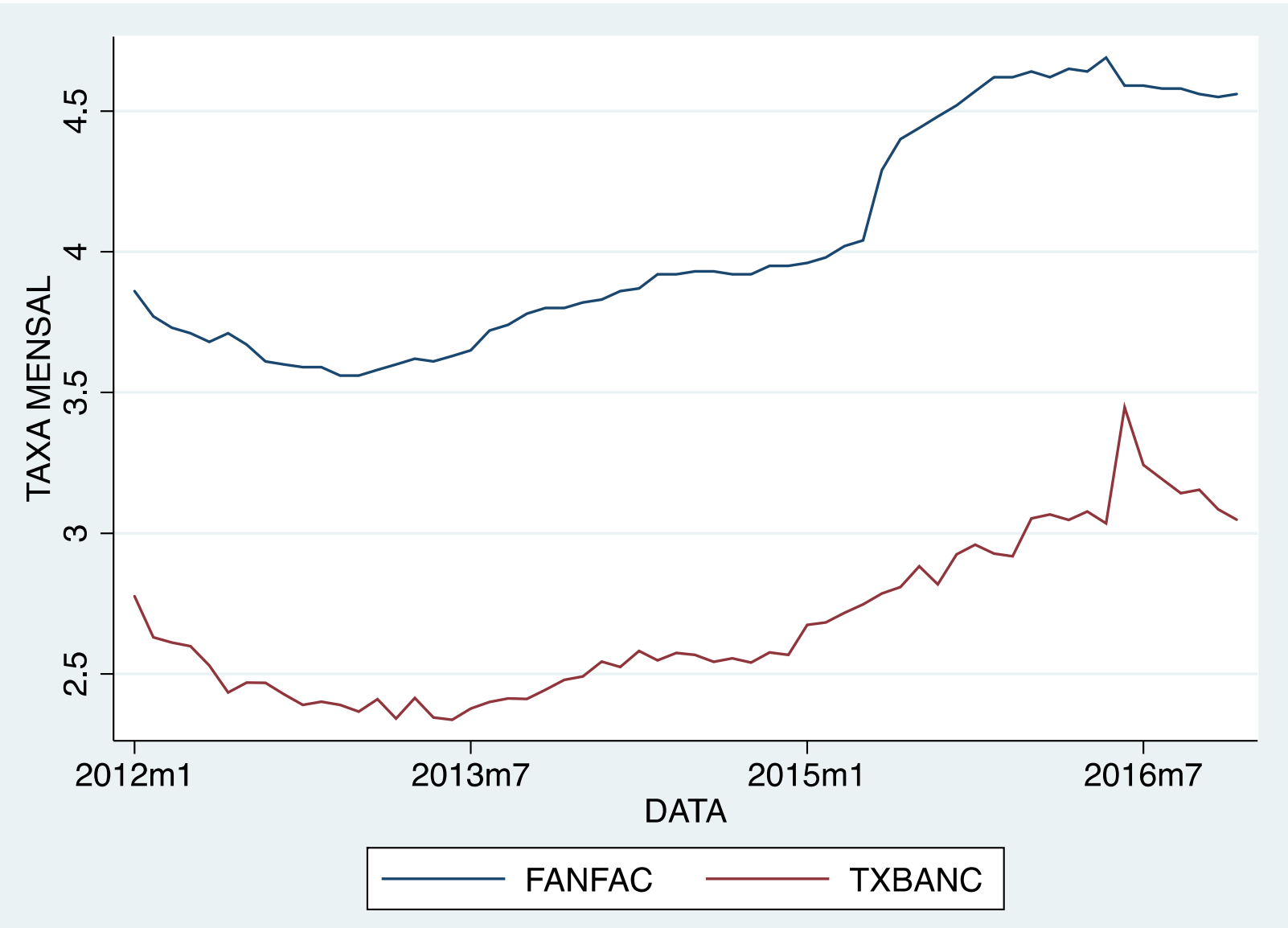

Figura 2. Evolução das taxas médias mensais ao longo do tempo

Os dados utilizados no referido trabalho são referentes a janeiro de 2001 até novembro de 2004. Segundo Dodl (2006), a obtenção do desconto de duplicata nos bancos possui um custo inferior à empresa cliente. Contudo, a utilização dos serviços de factorings pode ser explicada pela fragilidade nos controles gerenciais nas empresas contratantes do crédito, o que aumenta o risco de crédito e dificulta o processo de captação de recursos com os bancos. Além disso, as atividades prestadas pelas agências de fomento englobam uma série de análises de mercado. Contribuem para a administração das sociedades requerentes do crédito.

\subsection{Resultados dos testes estatísticos}

A próxima etapa da pesquisa foi a análise dos testes estatísticos. $O$ primeiro teste feito foi o de médias. Os seus resultados estão expostos na Tabela 2. 
Tabela 2

Resultados do teste de médias entre as taxas analisadas

\begin{tabular}{ccccccc}
\hline Variáveis & Obs & Média & $\begin{array}{c}\text { Erro } \\
\text { Padrão }\end{array}$ & $\begin{array}{c}\text { Desvio } \\
\text { Padrão }\end{array}$ & [Intervalo de Confiança de 95\%] \\
\hline ANFAC & 60 & 4,036333 & 0,051043 & 0,395380 & 3,934196 & 4,138471 \\
BACEN & 60 & 2,681918 & 0,036315 & 0,281295 & 2,609252 & 2,754584 \\
\hline Combinado & 120 & 3,359126 & 0,069474 & 0,761052 & 3,221560 & 3,496692 \\
\hline Dif & 60 & $1,354415^{*}$ & 0,062644 & & 1,230226 & 1,478605
\end{tabular}

Nota. * denota significância estatística a um nível de P-value< $1 \%$ bi-caudal.O teste estatístico utilizado foi o testet para amostras independentes com controle de homogeneidade de variância.

Percebe-se, com respaldo nos resultados, que a média do fator ANFAC é significativamente maior do que a taxa média cobrada pelos bancos. Ressalta-se que ambas as taxas são efetivas e já incluem todos os custos da operação de desconto, como, por exemplo, as tarifas cobradas pelas instituições. A diferença obtida entre as taxas médias foi de $1,35 \%$ e seu intervalo de variação é relativamente pequeno, conforme o erro padrão obtido. Infere-se, com base nos dados obtidos, que as taxas cobradas pelas factorings refletem o seu ambiente de risco e que elas transferem esse custo diretamente ao tomador de crédito, pois as taxas cobradas são significativamente maiores.

O segundo teste realizado foi o $\mathrm{D}$ de Cohen, a fim de avaliar a magnitude da diferença entre as variáveis. Conforme Cohen (1988), o tamanho do efeito é classificado em pequeno, médio e grande. Uma estatística com $D<0,20$ possui um efeito pequeno; entre $0,21<D<0,79$ um efeito médio e $D>0,80$ um efeito grande. Esta pesquisa apresenta um efeito de 3,95. Portanto, possui um padrão grande de distribuição em relação ao teste $\mathrm{D}$ de Cohen, conforme observado na Tabela 3.

Tabela 3

\section{Resultados do teste do tamanho do efeito}

\begin{tabular}{rccc}
\hline Tamanho do Efeito & Estimativa & [Intervalo de Confiança de 95\%] \\
\hline Teste de Cohen $(d)$ & 3,947438 & 3,305338 & 4,583145 \\
\hline
\end{tabular}

Nota. Segundo Cohen (1988), o tamanho do efeito possui o seguinte padrão médio de distribuição em relação ao resultado do DCohen: uma estatística $D<0,20$ representa um efeito pequeno; entre $0,21<D<0,79$ um efeito médio e quando ela for $D>0,80$ um efeito grande.

As evidências fornecidas pelo teste de Cohen (1988) corroboram a significância estatística das diferenças e indicam que o tamanho da diferença entre as taxas também é economicamente significativo para o tomador de crédito, ou seja, os critérios adotados na concessão do crédito afetam de modo relevante os tomadores na antecipação das agências de fomento em comparação com os tomadores na antecipação dos bancos.

Esses resultados corroboram os dos trabalhos teóricos de Stabile (2012) e Eckert et al. (2015). O custo de captação dos recursos por meio do desconto de recebíveis nas agências de fomento é significativa e economicamente maior do que nos bancos. Stabile (2012) aponta que entre os motivos que geram essa diferença estão o custo da maleabilidade, o que torna a operação mais cara e nem sempre vantajosa para quem precisa captar recursos. Eckert et al. (2015) também vão na mesma linha e destacam, com base no resultado da sua pesquisa, que companhias, as quais necessitam financiar seu capital de giro, o fazem nas factorings, principalmente, por possuírem restrições cadastrais, o que inviabiliza tais operações nos bancos. Além disso, os pesquisadores destacam que os respondentes também escolhem as agências de fomento porque possuem um limite de operação baixo nos bancos e nas factorings o processo é menos burocrático.

Para tentar entender um pouco os possíveis motivos de existirem diferenças tão significativas entre as taxas, foi feita uma análise de correlação das taxas utilizadas com algumas variáveis econômicas, como a taxa básica da economia e o indicador de inadimplência (Tabela 4). 
Tabela 4

Correlação entre as variáveis

\begin{tabular}{c|c|c|c|c} 
& ANFAC & BACEN & SELIC & INADIMPLÊNCIA \\
\hline ANFAC & 1 & & & \\
\hline BACEN & $0,9392^{*}$ & 1 & & \\
\hline SELIC & $0,9261^{*}$ & $0,878^{*}$ & 1 & \\
\hline INADIMPLÊNCIA & $0,7478^{*}$ & $0,8139^{*}$ & $0,5736^{*}$ & 1
\end{tabular}

Nota. * denota significância estatística a um nível de P-value $<1 \%$ bi-caudal.

Os resultados obtidos com o teste de correlação fornecem algumas inferências sobre a relação das taxas cobradas com outros indicadores. $O$ primeiro aspecto, que pode ser observado, é a maior correlação do fator ANFAC com a SELIC $(0,9261)$ do que a taxa cobrada pelos bancos com a SELIC $(0,878)$. Esse pode ser um aspecto relacionado com a maleabilidade e com o nível de sofisticação dos modelos de análise do risco de crédito. Uma maior correlação com a SELIC é um indício de que a taxa das factorings segue mais o panorama econômico global (risco de mercado) do que a taxa cobrada pelos bancos, que depende mais do seu próprio modelo de análise de crédito. Isso ficou claro também na correlação das taxas com 0 indicador de inadimplência. $O$ fator ANFAC é menos correlacionado com a inadimplência $(0,7478)$ do que a taxa dos bancos $(0,8139)$. Essa maior correlação indica que as taxas dos bancos variam de modo mais próximo da inadimplência do que o fator ANFAC e pode ser um reflexo de que os bancos transferem de modo mais tempestivo e com maior acurácia esse custo para suas taxas, o que não ocorre nas agências de fomento, por realizarem um processo mais flexível e menos burocrático de análise de crédito (Eckert et al., 2015).

\subsection{Análise de sensibilidade}

Para finalizar, foi feita uma análise de sensibilidade com as taxas cobradas pelos 6 maiores bancos comerciais no Brasil (Bradesco, Banco do Brasil, Banco Santander, Caixa Econômica Federal, HSBC Bank Brasil e Itaú Unibanco). Como a taxa média dos bancos envolvia todos os bancos com operações de desconto de duplicatas e cheques, seria possível que, pelo fato de envolver bancos com operações diversificadas, as taxas cobradas mais baratas e mais caras pudessem distorcer os resultados médios. Desse modo, foram selecionados os principais bancos (aqueles que têm a maior base de clientes, o que aumenta a probabilidade de serem procurados para esse tipo de operação), para se fazer uma análise de sensibilidade com as suas taxas médias. Os resultados dessa análise estão expostos na Tabela 5.

Tabela 5

Resultados da análise de sensibilidade

\begin{tabular}{ccccccc}
\hline Variáveis & Obs & Média & $\begin{array}{c}\text { Erro } \\
\text { Padrão }\end{array}$ & $\begin{array}{c}\text { Desvio } \\
\text { Padrão }\end{array}$ & \multicolumn{2}{c}{ [Intervalo de Confiança de 95\%] } \\
\hline ANFAC & 60 & 4,036330 & 0,051043 & 0,395380 & 3,934196 & 4,138471 \\
BACEN & 60 & 2,572373 & 0,046371 & 0,359190 & 2,479585 & 2,665162 \\
\hline Combinado & 120 & 3,304353 & 0,075375 & 0,825694 & 3,155103 & 3,453604 \\
\hline Dif & 60 & $1,463960^{*}$ & 0,068962 & & 1,327397 & 1,600523
\end{tabular}

Nota. * denota significância estatística a um nível de P-value $<1 \%$ bi-caudal. O teste estatístico utilizado foi o teste t para amostras independentes com controle de homogeneidade de variância.

Percebe-se, com base nos resultados, que houve um ligeiro aumento nas diferenças entre as taxas cobradas quando se levou em consideração apenas os grandes bancos, ou seja, a significância estatística permaneceu a mesma. 


\subsection{Avaliação e implicações dos resultados}

Os resultados obtidos pelo trabalho confirmam que existe uma diferença significativa e relevante entre a taxa cobrada pelas factorings (fator ANFAC) e a taxa média cobrada pelos bancos nas operações de antecipação de recebíveis. Entre os possíveis fatores que explicam essa diferença está o nível de sofisticação dos modelos de análise de risco empregados pelas agências de fomento e pelos bancos. No momento da antecipação dos recursos financeiros, bancos e factorings analisam as empresas clientes, as empresas devedoras do crédito e os títulos negociáveis de maneiras divergentes. Empresas que precisam de crédito e apresentam restrições cadastrais possuem maior dificuldade para operarem com bancos e acabam recorrendo às factorings como alternativa. Esse aspecto foi apontado na pesquisa de Eckert et al. (2015). Por outro lado, as instituições financeiras não costumam examinar as empresas devedoras pois entendem que essa análise já foi realizada pela empresa que cede o título para desconto. Já as factorings fazem a verificação do risco do crédito também com base no devedor do título, o que aumenta o escopo do seu serviço se comparado com dos bancos comerciais.

Trabalhos como os feitos por Wolf (2008) e Wloch (2006) também ressaltam algumas diferenças entre as atividades e destacam que a agência de fomento atua em conjunto com suas clientes, disponibilizando uma série de serviços não-creditícios, o que torna ambas parceiras de negócio, e isso poderia trazer um reflexo nas taxas cobradas. Segundo Dodl (2006), as empresas buscam inicialmente o capital de giro que precisam, porém o diferencial dos serviços da factoring encontram-se a longo prazo.

Para finalizar, outro ponto que pode ser considerado como razão para a diferença nas taxas aplicadas é o direito ou não ao regresso na factoring (caso o devedor não pague o título acordado, possui a instituição credora o direito, ou não, de cobrar o valor negociado de sua empresa cliente). Nos casos em que a empresa de fomento não puder regressar os valores dos recebíveis com suas empresas clientes, ela terá que assumir como perda o recebível adquirido e não quitado pela empresa devedora. Sobre o assunto, falta uma legislação específica que regule tal atividade, o que traz posições opostas tanto na jurisprudência quanto na doutrina. Nas instituições financeiras o tema é de consonância. Goulart \& Paulo (2011, p.296) citam que, "o banco tem direto de regresso contra o cedente do título no caso de inadimplência". Dessa forma, caso o devedor não cumpra sua obrigação de quitação, a instituição financeira cobra da empresa que fez o desconto do título. Fica garantido, assim, que não haverá perda no título descontado.

Todos esses fatores podem ser a força motriz por trás das diferenças encontradas entre as taxas nesta pesquisa. Destaca-se, contudo, apesar de tais fatores motivacionais e do papel que as factorings possuem como mecanismos de fomento em uma economia mais maleável e no meio das pequenas empresas (Batista \& Junior, 2012; Silveira, 2010), que as taxas cobradas por elas refletem maior risco. Para quem necessita antecipar seus recebíveis é mais viável economicamente procurar um banco comercial, pois os mesmos possuem uma taxa efetiva mais baixa. Caso o cliente não possua o score de crédito necessário ou tenha alguma restrição que impeça a cessão de crédito bancário a solução é antecipar os recebíveis em uma factoring.

\section{CONCLUSÕES}

Esta pesquisa teve como objetivo analisar a diferença entre as taxas médias utilizadas por bancos comerciais e empresas de fomento (factoring) na negociação de recebíveis das empresas no cenário brasileiro. O período analisado compreende os últimos cinco anos e foi analisado o quão diferentes são as taxas, assim como as possíveis explicações para o fenômeno observado.

Os resultados obtidos evidenciam que as variáveis principais, fator ANFAC e taxa bancária, seguem uma tendência similar de elevação ou diminuição ao longo dos períodos. Contudo, seus valores se diferem de modo relevante. O fator ANFAC das factorings, que é a taxa média cobrada para fazer a antecipação de recebíveis, é significativamente superior à taxa média efetiva cobrada pelos bancos, o que pode ser explicado pelo modelo de risco 
aplicado e as peculiaridades das duas atividades. Jorion (2011) e Hull (2015) apontam que existem diversos tipos de modelos para se analisar risco de crédito e que cada modelo deve ser adaptado ao apetite de risco da empresa que o analisa. Devido às diferenças entre as formas de financiamento, regulação e até a concepção de suas atividades é provável que os bancos e as factorings possuam modelos distintos. O modelo de risco bancário geralmente é bastante tecnológico e com maior exatidão, enquanto o modelo das factorings é mais maleável e menos burocrático, o que permite ser mais direcionado a cada situação das empresas clientes, porém a uma taxa superior. Esse aspecto transpareceu na análise de correlação que mostrou uma maior relação da taxa dos bancos com a inadimplência e menor com a SELIC, em comparação com a taxa do fator ANFAC, que se mostrou o contrário e apresentou uma maior correlação com a taxa básica e menor com a inadimplência.

No mercado, um reflexo dessa taxa significativamente maior cobrada pelas factorings é que as empresas acabam utilizando seus serviços em segunda instância ou quando apresentam alguma restrição cadastral que as impeçam de operar com os bancos (Stabile, 2012). Com isso, o risco envolvido na operação da factoring acaba sendo superior ao bancário e precisa ser repassado na taxa aplicada.

Uma limitação desta pesquisa é que não foi possível aprofundar sobre a composição das taxas aplicadas, verificando custo, risco e lucro de cada instituição. Outra limitação foi a pequena quantidade de trabalhos encontrados com temas relacionados. Como sugestão, outras pesquisas podem vir a fazer uma investigação mais focada nas taxas cobradas com modelos econométricos mais avançados, para tentar descobrir novidades nos comportamentos das referidas taxas. Outro ponto que pode ser aprofundado é um estudo mais direcionado a uma região ou setor de mercado específico, que busque auxiliar as empresas na gestão dos seus negócios.

\section{REFERÊNCIAS}

Anjos, L.C.M., Miranda, L.C., Silva, D.J.C.,\& Freitas, A.R.F. (2012). Uso da Contabilidade para Obtenção de Financiamento pelas Micro e Pequenas Empresas: Um Estudo a Partir da Percepção dos Gestores. Revista Universo Contábil, 8(1), 86-104.

Araújo, V.S. \& Machado, M.A.V. (2007). Gestão do Capital de Giro de Pequenas Empresas. Rev. Cent. Admin. 13(1), 48-61.

Associação Nacional de Fomento Comercial (ANFAC). (2017). Recuperado em 7 fevereiro, 2017, dehttp://www.anfac.com.br/v3/

Banco Central do Brasil (BACEN)(2017). Recuperado em 7 fevereiro, 2017, de http://www.bcb.gov.br/pt-br/\#!/home

Batista, R. S., \& Junior, J. F. B. R. (2012). A importância do Factoring para pequenas e médias empresas. Veredas Favip - Revista Eletrônica de Ciências, 5(1), 75-85.

Brito, G. A. S., Assaf, A. A., Neto \& Corrar, L. J. (2009). Sistema de classificação de risco de crédito: uma aplicação a companhias abertas no Brasil. Revista Contabilidade e Finanças, 20(51), 28-43.

Brito, G. A. S. \& Assaf, A. A., Neto (2008a). Modelo de classificação de risco de crédito de empresas. Revista Contabilidade e Finanças, 19(46), 18-29.

Brito, G. A. S. \& Assaf, A. A., Neto (2008b). Modelo de risco para carteiras de créditos corporativos. Revista de Administração, 43(3), 263-274.

Capelletto, L. R. \& Corrar, L. J. (2008). Índices de risco sistêmico para o setor bancário. Revista Contabilidade e Finanças, 19(47), 6-18. 
Cohen, J. (1988), Statiscal Power Analysis for the Behavioral Siences (2a ed.). New York: Lawrence Erlbaum Associates.

Cochrane, T. M. C. (2005, Julho 15). As empresas de factoring e as micro e pequenas e médias empresas: parceiras. Jornal o povo. Recuperado em 02 fevereiro, 2017, de http://www.planejamentotributario.ufc.br/

Dantas, J. A., Rodrigues, F. F, Rodrigues, J. M.,\& Capelletto, L. R. (2010). Determinantes do grau de evidenciação de risco de crédito pelos bancos brasileiros. Revista Contabilidade e Finanças, 21(52).

Decker, S.R.F. \& Gomes, M.C. (2014). Análise de Crédito Utilizando Mapas Cognitivos como Instrumento de Apoio ao Processo Decisório em uma Empresa de Factoring. Revista Produção Online, 14(3), 822-836.

Diário do comércio (2016). Crise abre oportunidade para empresas de factoring. Restrições de crédito tem levado gestores a recorrer à modalidade. Recuperado em 02 fevereiro, 2017, de

http://www.diariodocomercio.com.br/noticia.php?tit=crise_abre_oportunidades_para_empr esas_de_factoring\&id $=172753$

Dodl, A. V. B. (2006). A atividade de factoring no mercado brasileiro. Dissertação de Mestrado, Universidade Federal do Paraná, Curitiba, PR, Brasil.

Eckert, A.,Rizzon, F., Mecca, M.S.,\&Biasio, R. (2015). Motivações, Vantagens e Desvantagens da Captação de Recursos Financeiros em Factoring: Um Estudo de Caso. Revista Interdisciplinar Científica Aplicada, 9(2), 61-78.

Falcão, G. J. (2001). Legislação que regula as empresas de fomento mercantil ("factoring”) no Brasil (p. 4). Recuperado em 25 março, 2017, de http://bd.camara.gov.br/bd/discover

Gitman, L. J. \&Zutter, C.J. (2012). Principles of Managerial Finance(13aed.).Boston: Prentice Hall.

Gonçalves, E. B., Gouvêa, M. A.,\&Mantovani, D. M. N. (2013). Análise de risco de crédito com o uso de regressão logística. Revista Contemporânea de Contabilidade, 10(20), 139-160.

Gonçalves, G. de A. (2012). Factoring como alternativa fonte de recursos para o capital de giro da empresas. Graduação em Ciências Contábeis, Faculdade Cearense, Fortaleza, CE, Brasil.

Goulart, A. M. C., \& Paulo, E. (2011). Factoring. In I. S. Lima, G. A. S. F. de Lima, \&R. C. Pimentel (Org). Curso de Mercado Financeiro (Cap. 9, pp 289-315). São Paulo: Atlas.

Hull, J. C. (2015). Risk Management and Financial Institutions (4aed.).New Jersey: John Wiley\& Sons Inc.

InternationalAccounting Standards Board (IASB) (2014). International Financial Reporting Standards (9). Financial Instruments.

Jorion, P. (2011). Financial Risk Manager Handbook(6aed.).New Jersey: John Wiley \& Sons Inc.

Katayama, D. M. (2003). Modelos de Crédito Aplicados a Empresas de Factoring. Graduação em Administração de Empresas, Universidade de São Paulo, São Paulo, SP, Brasil. 
Lei no 9.430/96, de 27 de Dezembro de 1996 (1996). Dispõe sobre a legislação tributária federal, as contribuições para a seguridade social, o processo administrativo de consulta e dá outras providências. Brasília, DF. Recuperado em 5 janeiro, 2017, de http://www.planalto.gov.br/ccivil_03/leis/L9430.htm

Leite, L. L. (2011). Factoring no Brasil (12a ed., pp. 221-225). São Paulo: Atlas.

Lima, M. V. A., Ensslin, L.,\&Montibeller G., Neto (2008). Modelo multicritério para gerenciamento de risco por uma empresa de factoring. Revista de Economia e Administração, 7(3), 328-340.

Palmuti, C. R. \& Picchiai, D. (2012). Mensuração do risco de crédito por meio de análise estatística multivariada. Revista Economia, 26(2), 7-22.

Rotta, B.L. \& Lima, J.F. (2006). O Perfil das Empresas de Factoring na Cidade de Toledo (PR). Revista de Ciências Empresarias da UNIPAR, 7(2), 185-194.

Santos, C. dos (2014). Proposta de planejamento estratégico para uma pequena empresa de Factoring de São José - SC. Graduação em Administração, Centro Universitário de São José, São José, SC, Brasil.

Serviço de Apoio às Micro e Pequenas Empresas de São Paulo (SEBRAE-SP). (2014). Causa Mortis: o sucesso e o fracasso das empresas nos primeiros cinco anos de vida. $\begin{array}{lllll}\text { Recuperado em } 08 \text { Janeiro, } & 016,\end{array}$ http://www.sebraesp.com.br/arquivos_site/biblioteca/EstudosPesquisas/mortalidade/caus a_mortis_2014.pdf

Serviço de Apoio às Micro e Pequenas Empresas de São Paulo (SEBRAE-SP). (2010). Doze anos de monitoramento da sobrevivência e mortalidade de empresas. Recuperado em 08 Janeiro, 2016 , de http://www.sebraesp.com.br/arquivos_site/biblioteca/EstudosPesquisas/mortalidade/morta lidade_12_anos.pdf

Schrickel, W. K. (1997). Análise de Crédito: Concessão e Gerência de Empréstimos (3a ed., p. 25). São Paulo: Atlas.

Securato, J. R. (2002). Crédito: análise e avaliação do risco. São Paulo: Saint Paul.

Securato, J. R. \& Famá, R. (1997).Um procedimento para a decisão de crédito pelos bancos. Revista de Administração Contemporânea, 1(1).

Silva, José Pereira. (2014). Gestão e análise do risco de crédito (8a ed.). São Paulo: Atlas.

Silveira, M. da (2010). Como as empresas de Factoring podem funcionar como apoio ao crescimento das Micros e Pequenas Empresas brasileiras. Graduação em Ciências Contábeis, Universidade Federal de Santa Catarina, Florianópolis, SC, Brasil.

Sindicato das Sociedades de Fomento Mercantil Factoring do Estado de São Paulo (SINFAC SP). (2010). O que é Factoring?. Recuperado em 18 Janeiro, 2017, de, http://www.sinfacsp.com.br/v2/content.php?id_page=27

Souza, J. M. de (2015). Análise das Informações sobre o Risco de Crédito: Estudo de cão do Banco Santander. Graduação em Ciências Contábeis, Universidade de Brasília, Brasília, DF, Brasil. 
Stabile, H. H. (2012). Factoring: Um Estudo Desse Mecanismo de Apoio às Pequenas e Médias Empresas. Caderno de Administração Universidade Estadual de Maringá, 20(2), 38-50.

Taylor, M. (2013). Global Banks and Financial Intermediaries. InG. Caprio Jr. (Org.) Handbook of Key Global Financial Markets, Institutions and Infrastructure (Cap. 33, pp. 357 - 366). London: Elsevier.

Wloch, A. P. (2006). A utilização dos serviços de factoring na região de Tubarão-SC: um estudo de caso. Pós-graduação em MBA Gestão Empresarial, Universidade do Extremo Sul Catarinense, Tubarão, SC, Brasil.

Wolf, F. M. (2008). As práticas de análise para concessão de crédito numa empresa de fomento mercantil (factoring). Graduação em Ciências Contábeis, Universidade Federal de Santa Catarina, Florianópolis, SC, Brasil. 